\title{
Dr. Lindberg and Scholarly Publishing
}

\author{
Meg Moreland WHITE, ${ }^{a}$ Nancy K. RODERER M.L.S., ${ }^{\text {b.1 }}$ \\ and Sheldon KOTZIN M.L.S. ${ }^{\mathrm{c}}$ \\ ${ }^{a}$ Consultant and former President, American Medical Publishers Association \\ ${ }^{b}$ Johns Hopkins University (Emerita) \\ ${ }^{c}$ National Library of Medicine (Retired)
}

\begin{abstract}
Donald A.B. Lindberg M.D., Director of the U.S. National Library of Medicine (NLM) from August 1984-March 2015, had a remarkable vision for NLM's scope, goals, and function. This vision resulted in many external partnerships and initiatives with the publishing industry, commercial and non-profit, journal editors, and professional organizations. These partnerships ranged from ongoing collaboration and dialogue, such as the NLM Publisher's Committee and the International Committee of Medical Journal Editors (ICMJE). to the more practical, such as the creation of HINARI and the Emergency Access Initiative (EAI). Dr. Lindberg fostered partnerships outside the NLM to expand the use and reach of Library resources, including MEDLINE and ClinicalTrials.gov to support innovations in the processes that build them, and improve the quality of biomedical journals. Dr. Lindberg also encouraged the use of technology to enhance medical information and supported the early development of fully interactive publications. Attitudes that contained a measure of skepticism and distrust faded as collaborators came to have a better understanding of both NLM and their partners. This chapter discusses these relationships and accomplishments that NLM achieved working with publishers and other creators and disseminators of medical information under Dr. Lindberg's leadership.
\end{abstract}

Keywords: Donald A.B. Lindberg M.D., U.S. National Library of Medicine, MEDLINE, Scholarly Communication, Publishing, ClinicalTrials.gov

\section{Introduction}

Donald A.B. Dr. Lindberg M.D., Director of the U.S. National Library of Medicine (NLM) from August 1984-March 2015, had a remarkable vision for the NLM: its scope, goals, and function. One of his gifts was the ability to see beyond his own four walls, his own perspective, and continually take a broad view of how medical knowledge could impact human health on a global scale. He understood innately the power of partnerships, even among entities whose agendas might appear to be competing, as a means to an end. This chapter discusses these relationships and accomplishments that NLM achieved working with publishers and other creators and disseminators of medical information under Dr. Lindberg's leadership.

\footnotetext{
${ }^{1}$ Corresponding Author, Nancy Roderer, 3608 Norton Pl NW, Washington, DC 20016 USA; Email: nrodere1@jhmi.edu
} 


\subsection{The Literature Selection Technical Review Committee}

When he arrived at NLM, Dr. Lindberg learned that decisions not to index some journals for MEDLINE were a common topic of written complaints from editors and publishers, often forwarded by their U.S. Representatives and Senators. As the number of medical journals continued to grow, and as the use of the MEDLINE database to identify relevant articles increased, the scope of the journals indexed by NLM was of increasing concern to NLM, journal publishers, editors, journal article authors, and readers.

In 1984, NLM based its selection decisions on advice from a group of distinguished external consultants with little turnover. Dr. Lindberg did not fault the consultants' qualifications or recommendations, but he concluded NLM needed a more defensible process. In his clear-eyed view, deciding which journals to index was analogous to deciding which grant applications to fund. He thought it should be supported by an official advisory committee established through U.S. National Institutes of Health (NIH) procedures for grant review committees, in accordance with the Federal Advisory Committee Act.

At Dr. Lindberg's request, questions of indexing scope and the appropriate approach to selecting journals to index were considered by NLM and presented to the Board of Regents at its May 1987 meeting [1]. At that point, NLM received about 13,500 journals and indexed more than 3,300 of them for MEDLINE. More than half of the titles received were indexed by one or more of the 14 major scientific abstracting and indexing services at the time. Since the 1960s, NLM and outside experts had used criteria designed to quantify the scholarly quality and importance of the journals when considering which titles should be indexed. Meanwhile, publishers and editors were interested in having their journals indexed. Readers were interested, it was pointed out, that MEDLINE include quality articles relevant to them but exclude those not relevant. Given the variety of users and journals, this was a complex challenge. At NLM, the monthly Index Medicus had reached its maximum size for publication in one volume, and MEDLINE needed to be segmented into different files because of software limitations.

Stemming from these discussions, which included consideration of the future development of MEDLINE and other NLM databases, the Literature Selection Technical Review Committee (LSTRC) was formally established as a NIH chartered Federal Advisory Committee in 1988 to review journals for inclusion in Index Medicus and MEDLINE - and to advise NLM on journal-related issues. It took time and energy to convince NIH of the wisdom of using a Federal Advisory Committee for this purpose, but LSTRC has remained in place since 1988, surviving periodic efforts to reduce the number of NIH Advisory Committees.

The acronym and full committee name were intentional as Dr. Lindberg hoped it would sound so off putting that it would arouse little interest from government bureaucrats and, consequently, limited controversy. Meetings are announced in the Federal Register and meeting minutes are available, including the list of journals approved for indexing by NLM following the meetings. LSTRC is part of a transparent process of submitting a journal for coverage in MEDLINE that includes screening of the initial application and a check of technical and indexing requirements.

The results of LSTRC meetings were of considerable interest to publishers for many reasons, chief among them commercial, as inclusion in MEDLINE could increase manuscript submissions and greatly improve a journal's citation and impact factor. The latter interests were a precipitating factor in establishing periodic meetings between publishers and NLM staff that are discussed below. 


\subsection{NLM Publishers Committee and Seminar Collaboration}

In 1999, the American Medical Publishers Association (AMPA), a trade organization made up of medical and health sciences publishers, had questions about the NLM related to MEDLINE and the process to select and index in MEDLINE. Jack Farrell, AMPA President, approached Sheldon Kotzin, then NLM's Executive Secretary of the LSTRC, to inquire about MEDLINE and explore ways in which publishers might be able to collaborate with NLM to understand and support the review process. Although AMPA was a relatively boutique organization made up of primarily health sciences book publishers, Farrell was astute enough to engage the new head of the larger Association of American Publishers (AAP) and its new director, former U.S. Congresswoman Patricia Schroeder, as part of this endeavor. Under the banner of the NLM Medical Publishers Committee, the group initiated quarterly meetings with Dr. Lindberg and NLM staff, the first occurred in February 2000.

The Publishers Committee meetings regularly included reporting on decisions made by NLM after LSTRC meetings and discussions of trends in coverage. Through the panel, NLM came to have an increased understanding of the issues facing publishers as they established new journals, and publishers gained in their understanding of the complexities of relevant processes within NLM. The latter contributed to a shift towards more collaboration between NLM and the publishing community, which advanced one of Dr. Lindberg's stated goals.

Another ground-breaking result of this collaboration was the creation of joint seminars by the NLM and the Professional and Scholarly Publishing (PSP) division of the AAP. These day-long events were held in conjunction with the annual PSP meetings in Washington, D.C. and focused on shared challenges. The initial conference, focused on Archiving, was sold out with diverse attendees including NLM employees, publishing staff, vendors and service providers, as well as librarians.

"From the start, Dr. Lindberg understood what we were trying to do,' said Farrell. "We wanted to improve communication between the NLM and publishers and he fully jumped on board." Prior to these conversations, the relationship had been somewhat antagonistic, and was exacerbated by the central role of NLM's National Center for Biotechnology Information in establishing PubMed Central on behalf of NLM. Dr. Lindberg's leadership and understanding of the larger common goals of the two groups led to decades of productive collaboration. He frequently described the partnership using another of his nautical metaphors as "Clear sailing with everyone pulling in the right direction."

When the authors of this chapter undertook to organize the various topics they would cover, they debated a chronological approach versus a type of project approach. Either would bring out interesting aspects of the projects, but in the end it was felt that a roughly chronological approach would better demonstrate an important feature of the efforts, that is the growing spirit of collaboration that developed as all sat around the table in the NLM Board room and spoke frankly of their challenges and aspirations.

\section{Permanent Paper}

"The use of acid-free paper is the preventive medicine for reducing the problem of deterioration of publications and the threat of their being lost to the record of civilization forever, said Charles Kalina, NLM Special Projects Officer [2]. 
NLM has a fundamental responsibility to preserve the content of books, journals and other library materials in its collection scope. At the same time, a major threat to the survival of books and journals published since the mid-nineteenth century has been the deterioration of paper caused by residual acids it contains. In 1984, just prior to Dr. Dr. Lindberg's arrival, NLM's Library Operations Division launched a comprehensive transNLM preservation study which produced a 1985 plan for ensuring the preservation of the NLM collection. A survey of the physical state of the collection undertaken as part of the study identified more than 12 percent of the collection was too brittle to withstand even one more library use. This was significantly less than had been found in surveys of collections other research libraries, but it was destined to expand.

Recommendations for addressing this problem included microfilming deteriorating documents, conservation of rare and variable materials, continuing research into digitization and electronic storage which were not yet feasible as preservation mechanisms and mounting a campaign to encourage future publication on archival materials, e.g., acid-free or permanent paper for print publications [3].

Dr. Lindberg supported progress on all these fronts, but he focused on the "permanent paper campaign," where his personal involvement was likely to be important to success. At the same time some were skeptical that NLM could influence publishing practices, but reducing future problems appealed to Dr. Lindberg. The permanent paper campaign also presented a golden opportunity for positive collaboration with publishers.

The NLM Board of Regents was briefed on the preservation plan in late 1985 and approved a revised preservation policy in 1986 which stated: "NLM shall actively encourage the publishing industry to use more durable materials in the production of the biomedical literature."

Dr. Lindberg quickly recruited Charles Kalina to become NLM's resident expert on paper composition, production, and supply issues and provide key support for the campaign. Following a Board of Regents hearing on permanent paper at NLM in January 1987, with U.S. Congressmen William Natcher as keynote speaker, the Board established a Permanent Paper Task Force representing all stakeholders. Task Force Members and NLM staff members undertook a number of efforts, including individual contacts with editors and publishers of journals indexed in MEDLINE, to encourage more use of acid-free paper. Fortunately acid-free paper was becoming more available and economical at the time.

By 1991, considerable progress had been made: 80 percent of the U.S. journals indexed by NLM were acid-free [2]. In addition to emphasizing use of acid-free paper in biomedical journals, NLM played an important role in advancing its use in U.S. government publications. Progress would continue to be made over the years, aided in part by standards development and continuing conversations with stakeholders, including publishers.

\section{Errata, Retractions, and other Linked Citations}

"Fraud in scientific research is unacceptable and inevitable." [4].

Academic and research organizations, government and other agencies sponsoring research, individual publishers, authors and readers all have a vested interest in assuring the accuracy of the published literature. In the early 1980s, there were some celebrated cases of published articles that were subsequently repudiated due to evidence of scientific fraud. 
Effective in 1984, just prior to Dr. Lindberg's arrival, NLM began to index retractions of articles published in the journals covered by MEDLINE and connect them to the MEDLINE citations for the original articles. In 1986, the U.S. National Institutes of Health (NIH) and various universities developed procedures to address research misconduct, defined as: fabrication, falsification, and plagiarism. In 1988, the International Committee of Medical Journal Editors (ICMJE) issued a statement about when and how to issue retractions, including NLM-recommended specifications, e.g., a complete reference to the article being retracted [5]. Dr. Lindberg admired NLM's leadership in this area and approved its expansion.

Dr. Lindberg often spoke of the vital role NLM indexers played in contacting publishers about serious errors, e.g., dosage, in abstracts and in alerting users to articles with subsequently published errata or retractions. By placing such information in MEDLINE and creating links between the relevant citations, NLM also made readers aware of corrected articles, duplicate publications, article updates, expressions of concern, comments, patient summaries, and republished articles. In this way, the reader is alerted to other information relevant to an original article [6]. These communications and the policies supporting them were facilitated by NLM's role as a member of the ICMJE and the long-standing cooperation of its members.

\section{The International Committee of Medical Journal Editors (formerly the Vancouver Group) and the Expansion of ClinicalTrials.gov}

The ICMJE was founded as a collaboration of influential medical journals with a mission to standardize editorial guidelines for submissions to biomedical journals.

This elite group initially met in Vancouver, BC, and in 1979 issued the first version of the Uniform Requirements for Manuscripts Submitted to Biomedical Journals. The group had asked NLM to specify the required format for bibliographic references and invited NLM's Executive Editor of Index Medicus/MEDLINE to join the Committee, which established an enduring association between the two entities. The current ICMJE requirements, now called Recommendations for the Conduct, Reporting, Editing, and Publication of Scholarly Work in Medical Journals, reflected a scope that goes far beyond manuscript preparation, by veteran and new journal editors alike. As mentioned previously, ICMJE statements about retractions and errors supported NLM's efforts to index and highlight them.

Another important collaboration between NLM and ICJME involved ClinicalTrials.gov. In February 2000, NLM launched ClinicalTrials.gov in response to the U.S. Food and Drug Administration Modernization Act (FDAMA) of 1997. FDAMA required the NIH to create a public information resource on certain clinical trials regulated by the U.S. Food and Drug Administration (FDA). In a communication to Dr. Lindberg on September 1, 1998, NIH Director Harold Varmus asked NLM to assume responsibility for building the system, citing the Library's "rich experience in managing the AIDS CTIS [clinical trials information system] and its depth in information technology" [7]. FDAMA's intention was to give patients and their physicians better access to information about open clinical trials for serious and life-threatening conditions. The law required the registration of such trials if regulated by FDA, but it had no enforcement provisions.

In the early 2000s, some highly publicized papers published in ICMJE member journals were subsequently shown to have reported drug trial results selectively, which 
omitted the full disclosure of significant side effects in some patient groups. Registration at the outset of trial began to be viewed as a key initial step toward clinical trial transparency and meeting obligations to research participants. Registration reveals the existence of trials and their key pre-specified characteristics, enabling some assessment of the completeness of later reported evidence.

Angry their journals had been used to deceive, ICMJE members issued a policy statement in September 2004 requiring complete registration of a clinical trial in a "qualified registry" prior to admitting the first patient - as a pre-condition for subsequent publication of the trial's results in their journals [8]. This requirement applied to trials initiated on July 1, 2005 or later. The deadline for registering trials active on July 1, but not yet registered, was September 13, 2005.

The published ICMJE statement named ClinicalTrials.gov as the sole qualified registry then available, although it indicated other qualifying registries were on the horizon. In fact, ClinicalTrials.gov did not meet the ICMJE criterion of being open to all prospective registrants because registration was limited to trials with a U.S. location.

In response to the ICMJE action, Dr. Lindberg quickly made a decision to lift this limitation, which permitted the submission of trials without a U.S. location. He believed a global increase in trial registrations would make the database more valuable to the public, journal editors, and those engaged in systematic review of evidence.

Dr. Lindberg also understood the power of journal editors to compel the submission of research data, based on previous experience with sequence deposits in GenBank. As Dr. Lindberg anticipated, the ICMJE policy sharply increased the number of trials registered in ClinicalTrials.gov and the number of different organizations in the U.S. and elsewhere, who submitted registrations [9]. The ICMJE followed up its registration policy by providing helpful guidance about including trial registry numbers in articles about trials, facilitating links between PubMed and ClinicalTrials.gov. The Committee also clarified that submission of summary trial results to ClinicalTrials.gov and other registries did not constitute prior publication.

By design, the ICMJE was and remains a decentralized and non-bureaucratic organization. Membership is by appointment only, and the group has no officers or budget. NLM staff were active contributors to many ICMJE initiatives during Dr. Lindberg's tenure, although it is important to note that staff participating in the ICMJE initiatives typically were not directly responsible for NLM policy in these areas.

Dr. Lindberg encouraged the ICMJE to take a global and diverse view of medical information. Several ICMJE members have participated as mentors in the African Journals Partnership Program (AJPP), established in 2004 with funding from NLM and the NIH Fogarty International Center [10]. In 2013, the Ethiopian Journal of the Health Sciences, one of the journals mentored in the AJPP, was invited to join the ICMJE, a testament to Dr. Lindberg's enduring influence. The NLM remains a member of ICMJE.

\section{Structured Abstracts}

Beginning in 1975, NLM's MEDLINE database included author generated abstracts up to 250 words (400 words for certain cancer-related articles) with its journal article citations.

In 1987, R. Brian Haynes M.D. Ph.D., the noted informaticist and Professor at McMaster University School of Medicine, called for improved abstracts, ones that would represent the content of a paper in a manner more useful to the reader [11]. Most journals 
employed the IMRAD flow (Introduction, Methods, Results, and Discussion) but there was no particular structure within abstracts. Haynes sent his proposal to Edward Huth M.D., the editor of Annals of Internal Medicine who sought input from the Ad Hoc Working Group for Critical Appraisal of the Medical Literature. Their multinational members were interested in improving the communication of healthcare evidence [12]. Studies published at that time suggested most clinicians did not search the journal literature to solve problems that arose in the course of clinical practice [13].

Dr. Lindberg supported the writing of Structured Abstracts (SAs) as they gave MEDLINE users, including the growing number of individual health professionals searching via NLM's Grateful Med interface, bold category headings and greater detail on study design, selection and number of participants, interventions, outcome measures, key findings, and clinical applications. Not only were these abstracts better organized but they provided more substantive information, resulting in more access points for MEDLINE users. Harbourt and others explored the utility of the SAs in citation retrieval [14]. They noted that Dr. Lindberg waived the MEDLINE limit of 250 words per abstract, allowing full SAs regardless of length. Analysis suggested that articles with SAs contained an average of three more Medical Subject Headings (MeSH) terms compared to other abstracts for MEDLINE articles. So, the additional access points were likely to assist in bibliographic retrieval. As a result, Dr. Lindberg's decision to include entire SAs regardless of length contributed to publisher decisions to comply with and leverage this structure.

In 2010, Dr. Lindberg invited Brian Haynes to discuss SAs with NLM staff. By this date, SAs were used by many publishers and were widely accepted by MEDLINE users. NLM staff had taken steps that improved the display of SAs in citation retrieval. Also, the ICMJE recommendations endorsed their use in publications. The SA discussion with Haynes centered on NLM conducting more research, enhancing MEDLINE citation display, improving retrieval in MEDLINE/PubMed, and supporting use of SAs in published papers.

These efforts were successful and helped clinicians more efficiently identify articles most relevant to their clinical needs, a recurring theme for Dr. Lindberg.

\section{Clinical Alerts}

In some cases, early pre-publication clinical research results justify stopping a clinical trial and making immediate changes in clinical practice. Aware of the importance of getting such results out to the practitioner community in a way that did not jeopardize their later journal publication, NIH held a meeting in January 1991 to discuss how to alert the community of dramatic results of a clinical trial and to hear from journal editors about their concerns.

At the meeting, Dr. Lindberg offered NLM's assistance in disseminating such alerts using the MEDLARS system and the National Network of Libraries of Medicine (NN/LM). Coincidentally, two days after the NIH meeting, the U.S. National Institute of Child Health and Human Development requested assistance to distribute a clinical alert on pediatric AIDS to supplement its own press conference and direct mailing of an announcement. The first Clinical Alert was distributed on MEDLARS within 24 hours and also faxed to the 135 resource libraries in the NN/LM and mailed to all Network member libraries [15]. NLM worked with member libraries to encourage redistribution of the Clinical Alerts within their institutions. 
Clinical Advisories provided by NIH Institutes were later added to NLM's distribution system. While the means of distribution changed over the years, Clinical Alerts and Clinical Advisories continued to be distributed by NLM into 2014, after which $\mathrm{NIH}$ Institutes took responsibility for alerting users directly via their websites.

\section{Out of Crisis, Opportunity: Transitioning to Publisher-supplied MEDLINE Citations and Abstracts}

In the mid-1990s, MEDLINE was evolving as the speed of innovation and research was driving exponential expansion in the number of journals and papers published. A major part of the MEDLINE process was capturing in machine readable form the citation and abstract for each article selected for indexing. The majority of this machine-readable data was created for NLM via a contract with a third-party keyboarding firm.

In 1996, a protest by one of the firms vying for the keyboarding contract caused a stoppage in the work and data loading into MEDLINE, resulting in a significant backlog and few new citations being added to one of world's most invaluable databases. While the protest was being adjudicated, NLM was forbidden to purchase any interim outside assistance. NLM's staff scrambled to address the backlog, keying some data themselves, developing a scanning/optical character recognition (OCR) input stream, and requesting machine-readable data from publishers.

While the dispute with the contractor was resolved in NLM's favor, the experience caused Dr. Lindberg to reach two conclusions. First, the precision and skill of the keyboard contractors, even though performing relatively routine and low paid work, was not trivial. Second, he was determined to use technology and cooperation from the publishers to eliminate the dependency on keyboarding in the MEDLINE production process. Dr. Lindberg told the Board of Regents at a May 1996 meeting that while the input crisis was significant, MEDLINE and MEDLINE processes would emerge "smarter and stronger" [16].

Dr. Lindberg assigned lead responsibility for developing an OCR input stream to George Thoma Ph.D., Chief, Communication Engineering Branch in NLM's Lister Hill National Center for Biomedical Communications, and asked David Lipman M.D., Director of NLM's National Center for Biotechnology (NCBI), to work aggressively with publishers to submit machine readable data for their journals' citations and abstracts. While NLM had been working for a decade to set up a machine-readable input stream from publishers, the interruption of the keyboarding stream gave publishers a much stronger incentive to participate.

In 1996, Dr. Lindberg set an initial goal of obtaining machine-readable data for one third of citations and abstracts from each of three methods: scanning/OCR, electronic submissions from publishers, and double keyboarding. His goal was achieved in 1999.

By mid--2004, NLM was able to cancel the keyboarding input stream. By that time publishers were delivering 74 percent of citations and abstracts in electronic form. An unintended but very real consequence of the expansion in production bandwidth and reduction in input costs was the ability to expand MEDLINE to include more journal titles, including journals in subject areas such as physics, climate science, and engineering. This allowed MEDLINE to mirror shifts in research and the growing overlap in scientific disciplines. This expansion of MEDLINE's scope benefited publishers of all shapes and sizes. 


\section{Efficiencies in Indexing}

A large-scale activity within NLM's Library Operations over the years has been the description of articles from high quality medical journals to facilitate their retrieval. This indexing is a 150-year-old tradition and includes adding descriptive and subject data not supplied by the publisher when articles are submitted. Originally indexing was done exclusively by library staff and contractors, but as the volume of both indexing activity and information retrieval research grew, the Library began to explore the use of natural language processing in tandem with human efforts. Early initiatives in this arena led to the creation of a cross-library indexing initiative by Dr. Lindberg in 1996. This was of interest to journal publishers and the extended biomedical research community, as it provided opportunities to improve the quality and timeliness of indexing operations, while reducing costs [17].

The resulting system, the Medical Text Indexer (MTI), has provided automated indexing recommendations since 2002. It makes use of publisher supplied material, related citations, and the MeSH vocabulary via The Unified Medical Language System (UMLS) in a process resulting in an ordered list of recommendations of $\mathrm{MeSH}$ descriptors, supplementary concepts (mostly chemicals), and publication types available to indexers. Since 2011, it has been used without human indexing, but with the standard manual review process for a growing number of journals found to be amenable to this approach [18]. Ongoing statistics are kept on use of MTI and techniques for further refinement are addressed on an ongoing basis. Recently, NLM announced the MEDLINE2022 initiative, with the goal of fully automated indexing by April 2022.

\section{HINARI}

A World Health Organization (WHO) effort that began in the 1990's with concerns about WHO libraries getting online access to Elsevier journals expanded into a larger consideration about how publishers might support researchers in developing countries. This resulted in a partnership with publishers that created the Health InterNetwork Access to Research Initiative (HINARI). The framework of the Health InterNetwork in which HINARI was developed was introduced by the United Nations' Secretary General Kofi Annan at the UN Millennium Summit in 2000.

The framework's principles included multilateral and multi-sectoral partnership, a commitment to equitable price, transparent criteria for inclusion, respect for copyright, a common license agreement, a one-stop delivery mechanism, initial commitment by publisher partners to a minimum of 3-5 years, and integration with WHO global development efforts and the wider socio-economic context [19].

The development of HINARI was regularly discussed at the NLM Medical Publisher's Committee and Dr. Lindberg offered the assistance of the NLM PubMed staff in addressing the technical linkage challenges, using the PubMed LinkOut feature to make existence of HINARI full-text resources visible to qualified PubMed users. WHO played an administrative role, identifying eligible institutions, housing and maintaining the HINARI server and central functions. The BMJ group, a publishing partner, provided a staff member, which led in the development of a common license agreement. Yale University Library provided technical assistance and worked on training, Publishers were full partners in developing the framework, providing journals, and monitoring results. 
HINARI went live in 2002, offering content from 1500 journal titles from five publishers to qualifying health sector institutions in developing countries with the lowest GNP per capita, without charge. Publishers and journals were added over time, and provision was made for providing access to a second tier of qualifying institutions at significantly reduced prices. Currently, about 21,000 journals, 6,900 e-books and 115 other information resources are available to health institutions in more than 125 countries, areas and territories. The service benefits many thousands of health workers and researchers, and in turn, contributes to improving global health. The success of HINARI also led to the development of similar efforts covering research in agriculture, the environment, development and innovation and global justice, with the five dimensions collectively identified as Research4Life [20].

\section{The Emergency Access Initiative}

In addition to his long-term vision for the NLM, Dr. Lindberg never lost his ability to focus on practical solutions to short-term challenges. This pragmatic approach is evidenced by the creation and implementation of the Emergency Access Initiative (EAI).

In 2005, regions within the United States were devastated by Hurricanes Katrina and Rita. The humanitarian crisis these natural disasters created prompted significant response from both health care workers and health sciences libraries.

Individual libraries in the United States and elsewhere struggled to provide relief workers with health information resources and services, but first responders universally pointed to the need for a single strategy to deliver potentially life-saving treatment information. Leveraging the existing collaboration between the NLM and the Professional and Scholarly Division of the Association of American Publishers, the Emergency Access Initiative (EAI) was created to provide free, full-text access to the clinical information most needed by health care professionals and librarians responding to a disaster - and to serve as a temporary replacement for library collections rendered inaccessible by disaster. The EAI leveraged the partnership between the NLM and the Medical Publishers Committee to secure access to clinical content, primarily through eBooks and eBook databases. With the support of publishers, this coverage quickly expanded to include leading journals.

Conceived by the NLM as a resource to be used in a domestic disaster, the EAI was first deployed to respond to an international crisis on January 25, 2010, 13 days after a catastrophic earthquake struck the Caribbean Island nation of Haiti. The initial EAI activation period of one month was extended by an additional four weeks through March 19, 2010. During the two-month period, 2,835 visitors accessed the site, 554 more than once, for a total of 4,743 visits, and 88,473 page views.

The EAI has been activated multiple times since its inception. In addition to Haiti, the EAI has supported frontline workers responding to multiple international disasters, including flooding in Pakistan (2010); the cholera epidemic in Haiti (2011); an earthquake \& tsunami in Japan (2011); a typhoon in the Philippines (2013); an Ebola outbreak in West Africa (2014); an earthquake in Nepal (2015); hurricane Maria in Puerto Rico (2017); and hurricanes Harvey and Irma in the U.S. (2017).

The EAI embodies many of Dr. Lindberg's core principles, so much so that in his retirement address he cited EAI within a list of personal favorite NLM programs that were created during his directorship. 


\section{Interactive Publications}

Always attentive to the possibilities of new technologies and new uses of them, Dr. Lindberg and the NLM Publishers Panel held a number of discussions about interactive publication in the mid 2000's.

Dr. Lindberg understood the value of heart sounds in cardiology journals or moving images of gait and balance in interactive neurology journals. He recognized that a visualization of a scientific experiment had benefits compared to a verbal description. While it was estimated that interactive publications, with material manipulable by the reader, accounted for only two percent of the published basic science and clinical journal articles indexed by NLM in 2007, it was anticipated that this number would grow significantly [21]. The growth of interactive publications was seen as a challenge to both the publishing community and to NLM, although it could boost the potential for journal article readers to benefit from enhanced learning and understanding.

NLM undertook three complementary initiatives to provide platforms and tools for experimenting with interactive technologies and assess their impact on users [22]. One of these was an experiment carried out in collaboration with Elsevier and the Student National Medical Association (SNMA). The experiment included two stages. In the first, a group of medical students reviewed 12 articles published in three Elsevier medical journals and suggested desired enhancements to improve learning, enhancements that were then incorporated in one article if possible. The second stage involved experimental and control groups who viewed the original and modified article and were tested on their knowledge gain. While the experimental group took somewhat longer to complete the activities, their results showed comparatively statistically significant knowledge gains and acceptance of the experience.

In a related effort, NLM created a visualization and analysis tool called Panorama and submitted it to the Elsevier Grand Challenge contest conducted in 2008-9, which invited researchers to "prototype tools dealing with the ever-increasing amount of online life sciences information" [23]. The NLM submission was judged a semi-finalist. Despite recent efforts to include ancillary material and original data with research articles, publisher innovation in this area remains relatively insignificant.

\section{Conclusion}

Dr. Lindberg envisioned a world in which medical information could improve the life of all humanity. This vision impacted his leadership within the NLM and inspired many fruitful partnerships outside the Library. Dr. Lindberg's pragmatic and humble approach led to many projects and initiatives that live in the fabric of healthcare information in the U.S. and around the world.

\section{References}

[1] National Library of Medicine (U.S.). Board of Regents. Minutes of Board of Regents meeting., May 1987. [Internet] [cited 2021 September 28]. p. 9-12. Available from: https://www.nlm.nih.gov/hmd/manuscripts/nlmarchives/bor/1987.pdf .

[2] National Library of Medicine (U.S.). Program and Services Fiscal Year 1991. [Internet] [cited 2021 $\begin{array}{lllll}\text { September } & 28] & \text { p. } & 2 . & \text { Available }\end{array}$ https://www.nlm.nih.gov/hmd/manuscripts/nlmarchives/annualreport/1991.pdf 
[3] Humphreys BL, Arenales DW, Cain J, Parascandola J, Rotariu M, Thoma G, et al. Preservation of the biomedical literature: a plan for the National Library of Medicine. Bethesda, MD, National Library of Medicine, Oct. 1985. [Internet] [cited 2021 September 28]. Available from: http://resource.nlm.nih.gov/8511680

[4] Lindberg DAB. Retraction of research findings. Science. 1987 March 13; 235(4794):1308. DOI: 10.1126/science.234.4794.1308b.

[5] Retraction of research findings. International Committee of Medical Journal Editors. Ann Intern Med. 1988 Feb; 108(2):304.

[6] Kotzin S, Schuyler PL. NLM's practices for handling errata and retractions. Bull Med Libr Assoc 1989; Oct 77(44):337-342. PMID: PMC227483

[7] Varmus H M.D. (National Institutes of Health). Email communication to: Donald A.B. Lindberg M.D. (National Library of Medicine). 1998 September 1. Located at: History of Medicine Division. National Library of Medicine. Bethesda MD. MSC 627.

[8] DeAngelis CD, Drazen JM, Frizelle FA, Haug C, Hoey J, Horton R, et al.; International Committee of Medical Journal Editors. Clinical trial registration: a statement from the International Committee of Medical Journal Editors. JAMA. 2004 Sep 15;292(11):1363-4. DOI: 10.1001/jama.292.11.1363. Available from: http://www.icmje.org/news-and-editorials/clin_trial_sep2004.pdf

[9] Zarin DA, Tse T, Ide NC. Trial registration at ClinicalTrials.gov between May and October 2005. N Engl J Med. 2005 Dec 29;353(26):2779-87.

[10] Royall J. When spider webs unite, they can tie up a lion: NLM's work in information technology and health in Africa, 1997-2011. In: Humphreys BL, Logan RA, Miller RA, Siegel ER, editors. Transforming biomedical informatics and access to health information: Don Lindberg and the U.S. National Library of Medicine. Amsterdam: IOS Press; 2021.

[11] Haynes, RB. Improving reports of research by more informative abstracts: a personal reflection. J R Soc Med. 2017 Jun;110(6):249-254. DOI: 10.1177/0141076817711075.

[12] Ad Hoc Working Group for Clinical Appraisal of the Medical Literature. A proposal for more informative abstracts. Ann Intern Med. 1987; 106:588-604.

[13] Cowell DG, Uman GC, Manning PR. Information needs in practice: are they being met? Ann Intern Med 1985; 103:596-9.

[14] Harbourt AM, Knecht LS, Humphreys BL. Structured abstracts in MEDLINE, 1989-1991. Bull Med Libr Assoc 1995; 83:190-5.

[15] National Library of Medicine (U.S.). Board of Regents. Minutes of Board of Regents meeting. February 28-March 1, 1991. [Internet] [cited 2021 September 28]. p. 5-6. Available from: https://www.nlm.nih.gov/hmd/manuscripts/nlmarchives/bor/1991.pdf

[16] National Library of Medicine (U.S.). Board of Regents. Minutes of Board of Regents meeting. May 1996. [Internet] [cited 2021 September 28]. p.5. Available from: https://www.nlm.nih.gov/hmd/manuscripts/nlmarchives/bor/May1996.pdf.

[17] Aronson AR, Mork JG, Lang F-M, Rogers WJ, Jimeno-Yepes AJ, Sticco JC. The NLM Indexing Initiative: current status and role in improving access to biomedical information. Report to the Board of Scientific Counselors. Bethesda MD: Lister Hill National Center for Biomedical Communications, April 5, 2012. Available: https://ii.nlm.nih.gov/Publications/Papers/ii-bosc2012.pdf

[18] Mork J, Aronson A, Demner-Fushman D. 12 years on - Is the NLM medical text indexer still useful and relevant? Journal of Biomedical Semantics. 2017; 8(8). DOI: 10.1186/s13326-017-0113-5.

[19] Aronson B. WHO's Health InterNetwork Access to Research Initiative (HINARI). Health Information \& Libraries Journal. 2002; 19(3):164-165. DOI: 10.1046/j.1471-1842.2002.t01-1-00391.x.

[20] WHO/Hinari Website: www.who.int/hinari/en/

[21] Lindberg DAB Research opportunities and challenges. Methods Inf Med 2005;44(4):483-6. Available from: http://methods.schattauer.de/en/contents/archivestandard/issue/685/manuscript/504/show.html.

[22] Siegel ER, Lindberg DA, Campbell GP, Harless WG, Goodwin CR. Defining the next generation journal: The NLM-Elsevier interactive publications experiment. Inf Serv Use 2010 Jan 1;30(1-2):17-30. Available from: https:/www.ncbi.nlm.nih.gov/pmc/articles/PMC3001620/

[23] Thoma GR, Ford G, Antani S, Demner-Fushman D, Chung M, Simpson M. Interactive publication: the document as a research tool. Web Semant. 2010 Jul. 1;8(2-3):145-150. http://www.ncbi.nlm.nih.gov/pmc/articles/PMC2908409/. 